\title{
CATÁLOGO DE RIESGOS CLIMÁTICOS EN CANARIAS: AMENAZAS Y VULNERABILIDAD*
}

\author{
P. Dorta Antequera \\ Departamento de Geografía, Campus de Guajara \\ Universidad de La Laguna, 38071 La Laguna \\ pdorta@ull.es
}

Resumen: A pesar de la supuesta suavidad climática, los fenómenos meteorológicos adversos tienen graves consecuencias en Canarias. Aún así los estudios sobre estas cuestiones son sólo parciales. Es por ello por lo que en este trabajo se pretende analizar los riesgos climáticos más importantes haciendo especial mención a los últimos años. Se señalan las amenazas climáticas a las que está expuesto el archipiélago y se muestran los umbrales máximos esperados en cada uno de los fenómenos catalogados como riesgos. Asimismo, se exponen una serie de reflexiones sobre la vulnerabilidact. Como se verá, aunque el clima representa el principal atractivo turístico, las islas no están exentas de las manifestaciones atmosféricas más extremas y la vulnerabilidad aumenta año tras año.

Palabras clave: Canarias, riesgo climático, vulnerabilidad, fenómeno meteorológico adverso.

Abstract: In spite of the apparent climatic mildness, the frequency and intensity of the adverse meteorological phenomena have serious consequences in the Canary Islands. Even so the studies on these questions are only partial. For this reason we have tried to analyse the most important clinatic hazards, giving special attention to the last years. We attempt to show the climatic threats that the archipelago is exposed to and the expected maximum thresholds in each one of the phenomena catalogued like hazard. Moreover, we present a series of reflections concerning vulnerability. It will be seen, in spite of the importance of climate being a tourist resource, the islands are not free of more extreme atmospheric events and that its vulnerability increases year after year.

Keywords: Canary Islands, climatic hazard, vulnerability, adverse meteorological phenomena.

* Recibido: 11-12-06. Aceptado: 11-05-07. 


\section{Introducción}

En un territorio que constituye un destacado destino turístico basado en su elevada insolación y atmósfera estable, los riesgos climáticos suponen un problema medioambiental y socioeconómico de primera magnitud. En los últimos años se han repetido una serie de fenómenos meteorológicos extremos que han causado cuantiosas pérdidas económicas -más de 300 millones de euros entre 1999 y 2005- y alrededor de treinta víctimas mortales. Los más destacados, el temporal de viento de enero de 1999, las precipitaciones torrenciales de marzo de 2002 en Santa Cruz de Tenerife, la ola de calor de julio de 2004 y la tormenta tropical Delta en noviembre de 2005. Estos eventos, de inusitada intensidad, han supuesto un hito en la toma de conciencia social sobre los riesgos. Con este artículo pretendemos poner de manifiesto el estado de la cuestión en cuanto a las amenazas y al aumento de la vulnerabilidad.

Aunque ya es evidente que el cambio climático es una realidad en el que el hombre es el principal responsable como se señala el cuarto informe del IPCC y que es posible que la concatenación de varios eventos de extrema violencia en los últimos 6 ó 7 años sea una prueba o, al menos, un indicio de un probable cambio en los patrones de circulación atmosférica sobre las islas, los poderes públicos no deberían escudarse en éste para no asumir determinadas responsabilidades. Eventos de origen natural de consecuencias catastróficas han supuesto, suponen y supondrán, con toda seguridad, un rasgo más del clima de las islas. El presente trabajo no pretende estudiar el cambio climático -que requeriría, además, de un estudio específico, muy exhaustivo y de gran envergadura-, sino demostrar que los acontecimientos de esta indole se han sucedido a lo largo de la historia independientemente del calentamiento global. Incluso diversos autores señalan que no es constatable un aumento en el número o intensidad de los episodios (de precipitaciones) (Mayer, 1999 y 2002; Marzol, 1988, 2002). Sin embargo, sí es cierto que la sociedad canaria es cada vez más vulnerable ante las manifestaciones extremas del clima.

En este sentido tratamos de ordenar y exponer las cuestiones más destacadas sobre los riesgos climáticos. Pretendemos mostrar cuáles son las intensidades máximas estimadas que presentan las principales amenazas, cuál es su frecuencia, su origen y cómo son sus efectos sobre el territorio. Todo ello mediante una puesta al día de la bibliografía, de la información meteorológica disponible y con la incorporación de las últimas investigaciones propias al respecto, para terminar haciendo algunas reflexiones relativas a la vulnerabilidad. 


\section{Canarias: ¿clima de eterna primavera?}

El archipiélago canario basa toda su industria turística en su clima benigno, en especial por el diferencial térmico durante el invierno en relación a Europa occidental (Dorta, 2004), presentando unos rasgos caracterizados por: la suavidad de sus temperaturas medias, como consecuencia de la situación latitudinal y por estar bañado por una corriente oceánica fría; un predominio de situaciones anticiclónicas $y$, por tanto, de estabilidad atmosférica y precipitaciones en general escasas; elevada humedad del aire; vientos débiles o moderados, con predominio de los alisios y una alta insolación.

En principio, por tanto, y según muestran los folletos y campañas turísticas, se trata de un territorio "poco conflictivo" desde una óptica climática. Sin embargo, a pesar de la falta generalizada de lluvias y su suavidad térmica, si analizamos los datos meteorológicos en profundidad y nos alejamos de los valores medios resulta evidente que no sólo se dan fenómenos meteorológicos adversos, sino que además presentan una gran virulencia. Asimismo, determinados rasgos geográficos contribuyen a aumentar los efectos de las amenazas de origen climático, hablamos de:

- Un territorio montañoso, muy compartimentado, con algunos de los desniveles mayores del país.

- Una orografía compleja conformada por pequeñas cuencas hidrográficas.

- La precipitación muestra una tendencia muy acusada a la concentración temporal y espacial.

- El carácter impermeable del roquedo y el general escaso recubrimiento vegetal acrecienta los procesos de escorrentía y facilita el arrastre de materiales sólidos.

- La cercanía del mayor desierto del planeta, el Sáhara y, por tanto, al más importante manantial de aire cálido y de aerosol mineral (Gelado et al., 2003).

Por ello, en el análisis de las series históricas de las islas, es evidente el predominio de condiciones de atmósfera estable y temperaturas moderadas todo el año, pero también se hace patente que los fenómenos meteorológicos adversos presentan una frecuencia y, especialmente, una intensidad comparable a algunas regiones peninsulares en aspectos como la precipitación -torrencialidad y sequías-, las olas de calor, el viento y con una virulencia muy superior al resto del país en otros, como la llegada de nubes de polvo sahariano.

Pero además, en cuanto a la vulnerabilidad, el archipiélago muestra:

- Una de las mayores densidades de población de España, con un poblamiento muy concentrado en las dos islas capitalinas: Tenerife y Gran Canaria.

- Numerosos núcleos de población enclavados en pendientes acusadas, en fondos de valle o en desembocaduras de barrancos. 
- Un poblamiento muy disperso con una amplia red de transporte e infraestructuras de todo tipo.

\section{Las amenazas climáticas ¿achacables al calentamiento global?}

El catálogo de amenazas de origen climático en Canarias es relativamente amplio. Sin embargo, aunque es cierto que el clima de las islas se ha analizado descle la Climatología Sinóptica y Analítica y en especial en relación a las lluvias de manera muy exhaustiva y con destacadas aportaciones (Marzol, 1987, 1988, 1989, 2002, o Máyer, 1999, 2001, 2002), el tema específico de los riesgos "ha sido escasamente abordado" (Máyer, 2003b). Sólo recientemente, comienzan a elaborarse estudios con ese enfoque (Horcajada et al., 2000; Máyer, 2003a; Marzol, 2006) aunque con una óptica más directamente relacionada con la amenaza climática o con cuestiones muy específicas que con todo el proceso del riesgo.

En esta línea y siguiendo la clasificación de riesgos naturales expuesta por Ayala y Olcina (2002) y dentro de los riesgos físico químicos en la litosfera, hemos identificado la ocurrencia de diez posibles riesgos de origen meteorológico y climático en el archipiélago. De ellos, algunos de poca relevancia como las nieblas y la nieve en sectores muy concretos de algunas islas, fenómenos derivados de las tormentas eléctricas como rayos o granizo y, sólo puntualmente, podemos encontrar olas de frío, que por la situación latitudinal del archipiélago son escasas y de poca relevancia en general, aunque constatadas (Marzol, 1986) e incluso hay registro de muertes por bajas temperaturas (Máyer, 2003a). Así, realmente son cinco los más destacados, los que se erigen en auténticos riesgos puesto que se trata de amenazas con efectos, en ocasiones muy graves, en el sistema socioeconómico canario: las lluvias intensas y torrenciales, las sequías, los vientos fuertes, las olas de calor y las advecciones de polvo sahariano ${ }^{1}$. En el presente trabajo se hará un análisis de éstos últimos, con especial incidencia en los episodios más recientes como ejemplo de situaciones tipo.

\subsection{Los riesgos derivados de la precipitación}

La compleja orografía de cada isla da como resultado que los totales pluviométricos sean muy variados. Los sectores de altitud media orientados al Norte rondan los

\footnotetext{
${ }^{1}$ En la citada clasificación se hace referencia a "tempestades de polvo", pero hemos creído más conve niente usar el término "acivección de polvo sahariano" puesto que en la mayor parte de los casos aunque su inicio se deba a tormentas de arena su desplazamiento se produce en condiciones anticiclónicas o débilmente ciclónicas.
} 
$1000 \mathrm{~mm}$. anuales, mientras que las costas meridionales apenas llegan a los $100 \mathrm{~mm}$. Además, la irregularidad es, sin duda, la característica más sobresaliente de la lluvia. Los estadísticos más empleados para medirla muestran las cifras más altas del país. Por ejemplo, el coeficiente de variación en las estaciones principales registra valores medios de un $43 \%$ (Martín Vide, 1996), no obstante supera el $50 \%$ en algunos sectores de cumbre de las islas de mayor altitud, rebasa el $60 \%$ en las vertientes meridionales y el $75 \%$ en las costas sur, lo que da idea de la enorme diferencia interanual en las precipitaciones.

\subsubsection{Las lluvias intensas y torrenciales}

Las precipitaciones de elevada intensidad horaria que ocasionalmente afectan a algún sector de las islas suponen la principal amenaza climática. De hecho es el rasgo del clima de Canarias del que existe mayor número de trabajos publicados y al que dedicaremos más atención.

En el ámbito canario, las características geomorfológicas, van a presentar repercusiones significativas en la precipitación y sus efectos (Máyer y Romero, 2006). Los importantes desniveles, en especial en las cinco islas más occidentales, favorecen los movimientos ascendentes del aire y, en condiciones de inestabilidad atmosférica, la formación de núcleos convectivos. Además, la fuerte escorrentía actua sobre suelos carentes de vegetación -sobre todo en las vertientes meridionales- lo que unido al carácter impermeable del roquedo, genera la formación de avenidas que actúan sobre materiales fácilmente erosionables que son arrastrados por la lluvia. En última instancia, el consiguiente acarreo de abundante caudal sólido, incrementa la densidad y el poder destructivo del flujo. Además, en núcleos urbanos de fuerte pendiente, la falta de un drenaje adecuado ocasiona coeficientes de escorrentía elevados y tiempos de concentración muy cortos. Se originan así inundaciones-relámpago (Ayala, 2002a), fenómenos muy localizados espacial y temporalmente que suelen producirse en pequeñas cuencas de sólo algunas decenas de kilómetros cuadrados, lo que da lugar a la aparición de avenidas muy violentas. El $94 \%$ de las víctimas de inundaciones en España se producen en pequeñas cuencas (Ayala, 2002a) y éstas suponen la esencia del paisaje canario: Tenerife, por ejemplo, con una superficie de $2000 \mathrm{~km}^{2}$ posee casi 500 cuencas (Romero et al., 2004).

Las lluvias máximas en Canarias muestran valores muy elevados, superiores a la mayor parte del territorio peninsular, incluso cercanos a la costa mediterránea y País Vasco, los sectores de mayor intensidad de la precipitación a escala nacional. Santa Cruz de Tenerife se sitúa en el quinto lugar entre las capitales de provincia del estado, superada únicamente por Málaga, Alicante, Valencia y Bilbao. Resulta relativamente normal que en 24 ó 48 horas se registren totales iguales a las cantidades medias anuales. Se han recogido precipitaciones superiores a los $400 \mathrm{~mm} / \mathrm{dí}$ y son numerosos 
Cuadro 1. Muestra de precipitaciones máximas diarias en Canarias.

\begin{tabular}{|c|c|c|c|c|c|}
\hline Estación & $p m m$ & Fecha & Esiación & $P m m$ & Fecba \\
\hline \multicolumn{6}{|l|}{ Santiago del Teide-Tamaimo* } \\
\hline (TF) & 391.4 & $19 / 02 / 1952$ & Cuevas Blancas* (GC) & 334,7 & $15 / 02 / 1956$ \\
\hline Izaña (TF) & 360.0 & $11 / 11 / 1950$ & Lomo Aljorradero* (GC) & 302,1 & $23 / 10 / 1955$ \\
\hline Vilaflor* (TF) & 358.9 & $11 / 04 / 1977$ & Tenteniguada* (GC) & 268,2 & $23 / 10 / 1955$ \\
\hline Esperanza C.F. ${ }^{*}$ (TF) & 290.0 & $10 / 04 / 1977$ & La Retamilla* (GC) & 248,6 & $17 / 11 / 1962$ \\
\hline Las Cañadas-Parador* (TF) & 275.0 & $4 / 12 / 1991$ & Tamaraceite (GC) & 244.2 & $23 / 11 / 1955$ \\
\hline Las Cañadas-Boca Tauce $\mathrm{A}^{*}$ (TF) & 270.0 & $4 / 12 / 1991$ & Presa de Homos (GC) & 242,6 & $17 / 11 / 1962$ \\
\hline Anaga-Mercedes* $(\mathrm{TF})$ & 270.0 & $10 / 04 / 1977$ & San Bartolomé & 242,5 & $6 / 12 / 1991$ \\
\hline La Laguna (Instituto)* (TF) & 269.0 & $30 / 11 / 1922$ & Aeropuerto Gran Canaria (GC) & 85.0 & $28 / 09 / 1987$ \\
\hline Aeropuerto Los Rodeos (TF) & 260.3 & $10 / 04 / 1977$ & Guisguey* $(\mathrm{FU})$ & 158.0 & $19 / 09 / 1984$ \\
\hline Santa Cruz de Tenerife (TF) & 232,6 & $31 / 03 / 2002$ & $\begin{array}{l}\text { Puerto del Rosario-Aeropuerto } \\
\text { (FU) }\end{array}$ & 76.5 & $5 / 12 / 1991$ \\
\hline Aeropuerto Tenerife Sur (TF) & 136.0 & $19 / 11 / 1983$ & $\begin{array}{l}\text { Puerto del Rosario-Los Estancos } \\
\text { (FU) }\end{array}$ & 90.0 & $4 / 12 / 1991$ \\
\hline $\begin{array}{l}\text { Sauces-Espigón Atravesado* (LP) } \\
\text { Caldera de Taburiente }\end{array}$ & 450.0 & $27 / 02 / 1988$ & La Vegueta* (LZ) & 166,5 & $17 / 12 / 1972$ \\
\hline Taburiente $(\mathrm{LP})$ & 399.3 & $10 / 02 / 1978$ & Lanzarote-Aeropuerto (LZ) & 79.3 & $25 / 01 / 1980$ \\
\hline Mazo-Tigalate* (LP) & 350.0 & $17 / 12 / 1991$ & San Andrés* (EH) & 590.0 & $24 / 02 / 1988$ \\
\hline Sauces-Marcos y Cordero* (LP) & 330.8 & $4 / 12 / 1991$ & San Andrés-A* $(\mathrm{EH})$ & 400.0 & $26 / 02 / 1988$ \\
\hline Barlovento-C.F.* (LP) & 286.7 & $29 / 03 / 1990$ & San Andrés-B* (EH) & 370.0 & $27 / 02 / 1988$ \\
\hline S/C de La Palma-Velhoco* (LP) & 258.0 & $4 / 12 / 1991$ & Frontera-Llanía* $(\mathrm{EH})$ & 337.9 & $12 / 03 / 2001$ \\
\hline Breña Alta-Botazo* (LP) & 261.6 & $4 / 12 / 1991$ & Erese $^{*}(\mathrm{EH})$ & 280.2 & $10 / 03 / 1957$ \\
\hline Mazo-Rosas* (LP) & 250.0 & $28 / 02 / 1988$ & $\begin{array}{l}\text { Aeropuerto Los Cangrejos } \\
\text { (EH) }\end{array}$ & 280.0 & $27 / 02 / 1988$ \\
\hline Sauces-San Andrés* (LP) & 250.0 & $15 / 01 / 1957$ & $\begin{array}{l}\text { S. Sebastián Faro de } \\
\text { S. Cristóbal* (LG) }\end{array}$ & 320.0 & $1 / 11 / 1960$ \\
\hline Mazo-Aeropuerto (LP) & 183.6 & $19 / 02 / 2004$ & & & \\
\hline
\end{tabular}

Fuente: INM, Elizaga Rodríguez, F, 2003 y Servicio Hidrâulico de Las Palmas de Gran Canaria. "Estaciones secundarias. LP: La Palma; EH: El Hierro; LG: La Gonera; TF: Tenerife; GC: Gran Canaria; FU: Fuerteventura; LZ: Lanzarote.

los puntos que han sobrepasado los $250 \mathrm{~mm} /$ día (cuadro 1). Incluso los sectores teóricamente más secos alcanzan valores muy destacados. En la mayor parte del territorio canario ya se han registrado cantidades superiores a $150-200 \mathrm{~mm}$ en cualquier orientación y a cualquier altitud. Sólo algunas áreas del litoral meridional y espacios más amplios de Lanzarote y Fuerteventura no llegan a esas cifras. Todo ello a pesar de que la mayoría de los datos meteorológicos no comienzan de manera sistemática y generalizada hasta bien entrado el siglo XX.

En épocas anteriores, sin datos numéricos disponibles, existen referencias importantes y abundante información histórica -crónicas de viajeros e historiadores, documentos oficiales, etc-- que aluden a las consecuencias de las precipitaciones torrenciales. Gracias a ellos hay constancia de violentos eventos de efectos catastróficos a 
lo largo de la historia con daños severos en infraestructuras y cuantiosas víctimas. Es el caso de la destrucción de numerosos puentes en las dos capitales provinciales arrasados por la fuerza del agua (Cola, 1986 y Máyer, 2003b), o las 130 inundaciones y 20 muertos que ha sufrido la ciudad de Santa Cruz de Tenerife desde 1550 (Marzol, 2002). Asimismo es relevante el rastro que dejan las riadas y avenidas en las formas de relieve, lo que demuestra que este tipo de fenómenos meteorológicos han sido una constante a escala del archipiélago y algo normal en el clima de Canarias.

Entre los episodios históricos más catastróficos destacan el aluvión de 1645 que, aunque con información escasa, parece ser que tuvo efectos devastadores con cientos de víctimas (Romero y Yanes, 1995) y, de manera especial, el temporal de noviembre de 1826 en todo el archipiélago -sobre todo en Tenerife-, cuyas precipitaciones originaron la muerte de centenares de personas, estimadas sólo en el Valle de la Orotava, en más de 200 (Quirantes et al,, 1993). Este aluvión, con innumerables referencias históricas, ha sido con toda probabilidad el fenómeno meteorológico adverso de peores consecuencias para las islas. Pero no son los únicos, como se observa en el cuadro 2.

Cuadro 2. Episodios de precipitaciones torrenciales más significativos en Canarias entre 1580 y 1949.

\begin{tabular}{|c|c|c|c|c|}
\hline S.XVI & S. XVII & S. XVIII & S. $X I X$ & $1900-1950$ \\
\hline 1581 (LPGC) & 1615 (LPGC) & \multicolumn{2}{|c|}{$\begin{array}{l}26-27 / 01 / 1713 \text { (LLTF y LPGC; sd) } \\
\text { (LPGC) }\end{array}$} & 1813 (LZ) 12/04/1901 \\
\hline \multirow[t]{2}{*}{$1590(\mathrm{TF})$} & $11 / 12 / 1645$ & & & \\
\hline & $(\mathrm{TF} ;>100)$ & $25 / 10 / 1722$ (TF y GC) & $1815(\mathrm{TF})$ & 13//01/1903 (LPGC) \\
\hline \multirow[t]{18}{*}{1594 (SCTF) } & 1646 (LPGC; sd) & 01/11/1749 (LLTF) & $1821(\mathrm{TF})$ & 12/04//1904 (LPGC) \\
\hline & 1694 (LPGC) & $1750(\mathrm{SCTF})$ & $\begin{array}{l}7-8 / 111826(\mathrm{TF} \\
200-600 ?)\end{array}$ & 09/11/1906 (LPGC) \\
\hline & & $1752(\mathrm{SCTF})$ & Nov 1829 (SCTF) & $02 / 01 / 1910(\mathrm{GC} ; 1)$ \\
\hline & & 1759 (SCTF) & $03 / 1837$ (SCTF) & 07/02/1912(GC) \\
\hline & & 06/01/1766 (LPGC) & $1849(\mathrm{LLTF})$ & 12/12/1917 (LPGC) \\
\hline & & $1773(\mathrm{SCTF})$ & $18-19 / 11 / 1851(\mathrm{GC})$ & 02/03/1920 (LPGC) \\
\hline & & 1775 (LPGC) & $23 / 12 / 1851$ (LPGC) & $29 / 11-01 / 12 / 1922(\mathrm{~T})$ \\
\hline & & 1778 (LPGC) & $06 / 12 / 1853$ (SCTF) & 16/11/1924 (LPGC) \\
\hline & & 1779 (LPGC) & $12 / 12 / 1859$ (SCTF) & 26/11/1925 (LPGC) \\
\hline & & $1780(\mathrm{LP})$ & 06/01/1866 (LPGC) & $16-17 / 01 / 1926(G C ; 6)$ \\
\hline & & $21 / 02 / 1781(\mathrm{TF} ; 1)$ & $03 / 1867$ (SCTF) & $22 / 10 / 1944(\mathrm{~T})$ \\
\hline & & 09/10/1783 (LP; 3) & Oct-Dic 1879 (TF, & \\
\hline & & & LPGC; 5) & 04/05/1944 (SCTF) \\
\hline & & 25/03/1791 (LPGC) & 09/11/1884 (LPGC) & $14 / 10 / 1945(\mathrm{GC})$ \\
\hline & & $14 / 16 / 10 / 1792(\mathrm{LP})$ & $13 / 10 / 1890(\mathrm{GC})$ & $30 / 11 / 1946(\mathrm{GC} ; 4)$ \\
\hline & & 12/11/1798 (LPGC) & $05 / 03 / 1894(\mathrm{GC} ; 1)$ & \\
\hline & & & 18/02/1896(GC) & \\
\hline & & & $1899(\mathrm{TF})$ & \\
\hline
\end{tabular}

Fuente: Máyer, 1999; Máyer, 2003a y 2003b; Quitantes et al. 1993 ; Marzol, 2002, Consejo Insular de Aguas, 2005; Cola, 1986 y numerosos textos antiguos. Entre paréntesis la ciudad/isla más afectada. GC: Gran Canaria; TF: Teneife; LP: La Palmal; LZ: Lanzarote; T: más de tres islas; LPGC: Las Palmas de Gran Canaria; SCTF: Santal Cruz de Tenerife; LLTF: La Laguna. El número entre paréntesis indica la cantidad de víctimas mortales. sd: hay constatación de muertos pero no está precisado el número exacto. 
Las lluvias de los últimos 60 años - periodo con datos meteorológicos- suponen el apartado mejor estudiado hasta la fecha; por ello sólo señalamos algunas de las características más sobresalientes.

Desde 1950 podemos destacar medio centenar de episodios de consecuencias catastróficas repartidas por todo el archipiélago. En el cuadro 3 aparecen los más significativos en función de la bibliografía existente, de sus efectos y de las precipitaciones máximas absolutas de los observatorios consultados ${ }^{2}$. En la evolución de las precipitaciones podemos comprobar como los años 50 fueron especialmente lluvio-

Figura 1. Precipitación horaria y total porcentual acumulada en Santa Cruz de Tenerife el 31 de marzo de 2002.
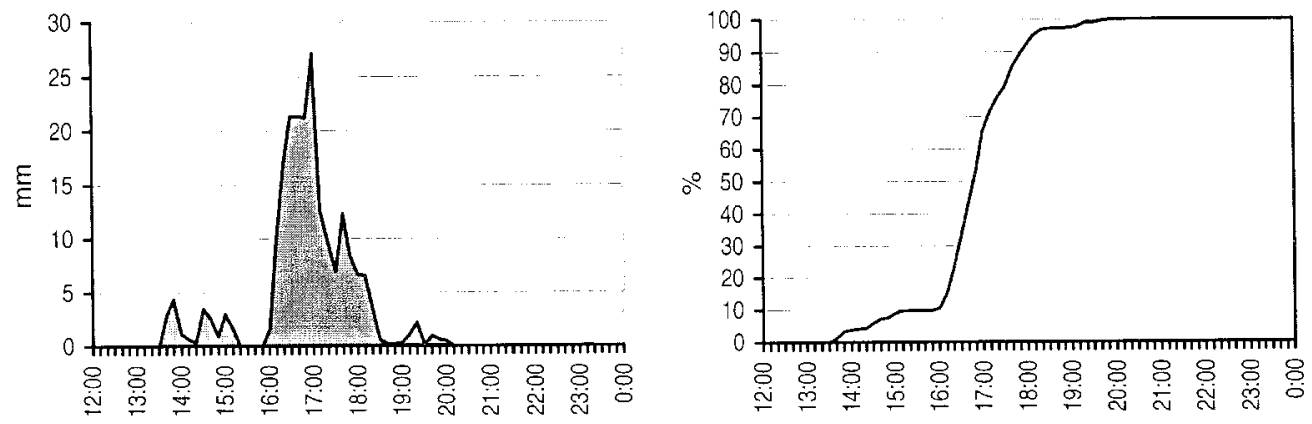
Fuente: INM.

Figura 2. Precipitaciones máximas en 24 horas en Santa Cruz de Tenerife (1938-2002) y Las Palmas de Gran Canarai (1951-2002).
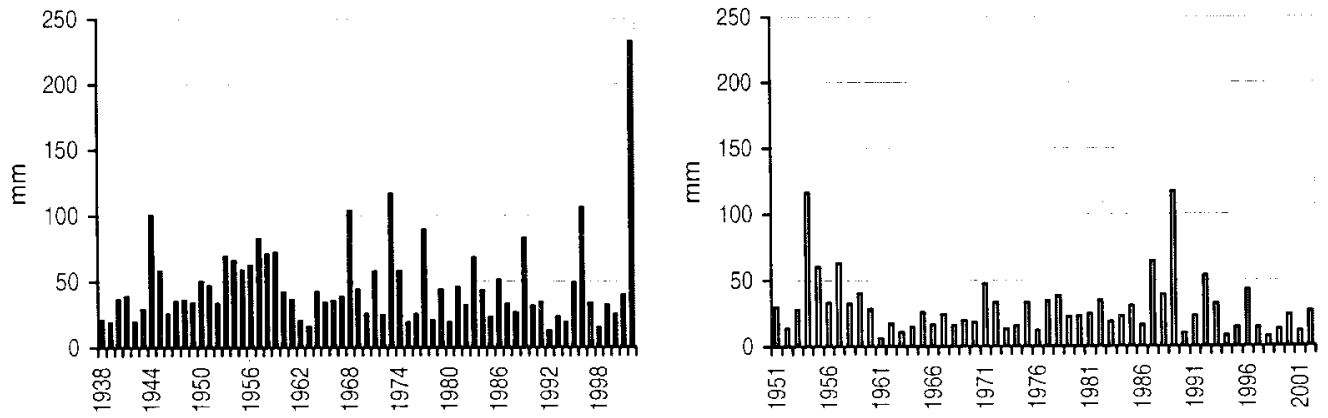

Fuente: INM y Servicio Hidráulico de Lás Palmas de Gran Canaria.

\footnotetext{
${ }^{2}$ También se ha consultado el informe final del Proyecto de Investigación "Impacto geográfico de los aluviones históricos en Canarias" ( $\left.n^{\circ} 264 / 93\right)$ que amablemente nos han cedido los autores.
} 
sos y catastróficos (Marzol, 1988; Máyer, 2003a y 2003b), siendo, sin duda, la década de mayor pluviometría en el archipiélago. Además, en estos años se produjeron la mayor parte de las víctimas mortales durante el siglo XX como consecuencia directa de la lluvia. Todos los eventos se han producido entre septiembre y abril, siendo especialmente numerosos de noviembre a febrero.

De entre todos estos temporales, presentaron especial gravedad los de noviembre de 1954, enero de 1957, noviembre de 1968, abril de 1977, febrero de 1989 y marzo de 2002. El de 1957 ha sido el episodio de precipitaciones torrenciales más grave del siglo XX en cuanto a sus consecuencias. Las lluvias se concentraron en el Este de La Palma, donde se superaron los $500 \mathrm{~mm}$ en 48 horas dando lugar a la pérdida de 32 vidas (Marzol, 1988).

Pero el episodio de mayor intensidad horaria -datos de pluviógrafo- registrado en el archipiélago y el de mayor volumen total de precipitación en la ciudad de Santa Cruz de Tenerife en los últimos 70 años ha sido el del 31 de marzo de 2002. Ese día la localidad sufrió la peor catástrofe natural de su historia reciente, al superarse los $250 \mathrm{~mm}$ en algunos puntos (Elizaga, 2003) -232,6 $\mathrm{mm}$ en el Centro Meteorológico Territorial de Canarias Occidental-, de los cuales la mayor parte cayó en algo más de dos horas (figura 1) con intensidades máximas de hasta $160 \mathrm{~mm} / \mathrm{h}$. La precipitación, afectó únicamente a una parte de la costa meridional del municipio, de manera que sólo cayeron $34,5 \mathrm{~mm}$ en La Laguna a $9 \mathrm{~km}$ de la capital. Elevada concentración espacial que es habitual en el clima de las islas como se ha observado en otros eventos (Horcajada et al., 2000). Los daños fueron muy cuantiosos: 250 viviendas afectadas, más de 120 millones de euros en pérdidas (Marzol, 2002), ocho muertos y 30 heridos.

Podemos apreciar la magnitud del episodio si tenemos en cuenta que se trata de una cantidad que supuso el doble de la máxima precipitación registrada hasta ese momento $-116 \mathrm{~mm}$ en febrero de 1973- igual a la media anual y siete veces superior a la lluvia de marzo (figura 2). Estadísticamente el valor alcanzado supone aparentemente un outlier, puesto que se desvía claramente de la recta de probabilidad correspondiente (Ayala, 2002b). Sin embargo, analizando las repercusiones de las lluvias históricas en Canarias, podemos afirmar que no resulta ser un valor tan extraño, porque precipitaciones de esa entidad se han dado en numerosos puntos del archipiélago a lo largo de los cinco últimos siglos, como ya hemos tenido ocasión de comprobar. Además, a pesar de la extrema gravedad del episodio existen referencias sobre precipitaciones en Santa Cruz de Tenerife que pueden indicar lluvias de similar intensidad, tales como las de noviembre de 1826 , ya señaladas, o diciembre de 1922 (Cola, 1986). Asimismo, si analizamos las series extensas de otros observatorios podemos comprobar que no es extraño que destaquen de forma importante muy pocos años sobre el resto. Es lo que ocurre en Las Palmas de Gran Canaria, ciudad en la que también dos años sobresalen nítidamente -1954 y 1989-(figura 2). Es un 
claro síntoma de que lluvias de este tipo constituyen una característica no tan extraordinaria como podría parecer en un principio.

El análisis estadístico de la serie de datos de Santa Cruz de Tenerife pone de manifiesto que los periodos de retorno, como ya señalan numerosas publicaciones, en especial del levante español, no son válidos para estimar precipitaciones máximas en regiones en las que la irregularidad es alta, con desviaciones típicas realmente extraordinarias y con series cortas, como es el caso canario. Además los periodos de retorno sólo son fiables si no se supera el doble de la longitud temporal de la serie analizada (Ayala, 2002b). Así, con los datos anteriores al año 2002 las intensidades máximas sólo preveían lluvias de más de $200 \mathrm{~mm}$ en periodos de retorno cercanos a los dos milenios.

Los estudios publicados sobre precipitaciones en Canarias señalan que la mayor intensidad horaria se da, sobre todo, en las vertientes orientales a altitudes medias. El origen de estas situaciones y su gran inestabilidad está generada por una acusada vaguada o depresión fría en altura que crea importantes diferencias térmicas con las capas más bajas. En algunos momentos, incluso, puede existir combinación con factores tropicales, entendidos estos como un descenso acusado de masas de aire o también combinación con aire tropical continental. Por ello, con frecuencia, la componente dominante en superficie es del Sur (SE o SW), tal como ocurrió, por ejemplo, con las precipitaciones extraordinarias de febrero de 1971, abril de 1977, febrero de 1989 o marzo de 2002 (figura 3). El gran contraste térmico, $-20^{\circ} \mathrm{C}$ a 5500 metros y temperaturas superiores a $\operatorname{los} 20^{\circ} \mathrm{C}$ a nivel del mar- que favorece la evaporación y alimentan la inestabilidad (Marzol, 2002), es el responsable de la fuerte intensidad de la lluvia y sus graves efectos sobre el territorio, a lo que se añade el papel del relieve en el favorecimiento de la convectividad, como ya se ha señalado.

\subsubsection{Las sequías}

Otro de los riesgos climáticos de gran frecuencia en las islas y de importantes efectos son las sequías meteorológicas. Éstas, en cuanto a su intensidad como a su duración, constituyen otro de los principales rasgos del clima de Canarias y su entidad es equiparable a los episodios de falta de lluvias más intensos del país, por ejemplo diecisiete meses consecutivos sin precipitación en el sur de Tenerife a mediados de los 70 (Marzol, 2001a). Es posible encontrar años extremadamente secos seguidos de otro muy lluvioso y viceversa, lo cual se puede observar mediante el índice de disparidad consecutiva (Martín Vide, 1996) con el que se obtienen valores medios semejantes a los del levante español (Marzol, 2002).

El estudio de los periodos de déficit hídrico es sabido que es muy complejo, precisamente por la diferencia entre duración e intensidad así como de los umbrales para 
Cuadro 3. Principales episodios recientes de lluvias intensas en Canarias (1950-2004).

\begin{tabular}{|c|c|c|c|c|c|c|c|c|c|c|c|c|}
\hline & Ene & $F e b$ & Mar & $A b r$ & May & Jun & Jun & Ago & Sep & $O c t$ & Nov & Dic \\
\hline 1950 & & & & & & & & & & & 10 & \\
\hline 1952 & & 29 & & & & & & & & & & \\
\hline 1953 & & & & & & & & & & & & $3 \mathbf{0}$ \\
\hline 1954 & & & & & & & & & & & $4 \mathbf{0}$ & \\
\hline 1955 & & & & & & & & & & 50 & & \\
\hline 1956 & & 6 & & & & & & & & & & \\
\hline 1957 & 70 & & 8 & & & & & & & & 9 & 10 \\
\hline 1960 & & & & & & & & & & & 119 & \\
\hline 1964 & 12 항 & & & & & & & & 130 & & & \\
\hline 1968 & & & & & & & & & & & $14 \mathbf{0}$ & \\
\hline 1971 & & 150 & & & & & & & & & 16短 & \\
\hline 1972 & & & & & & & & & & & & 177 \\
\hline 1973 & & 18 & & & & & & & & & & \\
\hline 1977 & & & & 190 & & & & & & & & \\
\hline 1978 & & 20 & & & & & & & & & & \\
\hline 1979 & $21 \mathbf{0}$ & & & & & & & & & & & \\
\hline 1980 & 220 & & & & & & & & & & & \\
\hline 1983 & & & & & & & & & & & 23 & \\
\hline 1984 & & & & & & & & & 24 & & & \\
\hline 1987 & & & & & & & & & & 25 & 26数 27 w & \\
\hline 1988 & & $28 \mathbf{0}$ & & & & & & & & & & \\
\hline 1989 & & 290 & & & & & & & & & 30 & 31 \\
\hline 1990 & & & 32 & & & & & & & & & \\
\hline 1991 & & & & & & & & & & & & 33 解 34 \\
\hline 1992 & & & & & & & & & & 350 & & 36 \\
\hline 1993 & & & 37糙 & & & & & & & 386 & & \\
\hline 1994 & & & & & & & & & & & & \\
\hline 1995 & & & & & & & & & & & & 390 \\
\hline 1996 & & $40 \mathbf{0}$ & & & & & & & & & & \\
\hline 1999 & $41 \%$ & & & & & & & & & $42 \circ$ & & 435 \\
\hline 2000 & 44 & & & & & & & & & & 45 & \\
\hline 2001 & & & $46 \%$ & & & & & & & & $47 \mathbf{0}$ & \\
\hline 2002 & & & $48 \mathbf{0}$ & & & & & & & & & \\
\hline 2004 & & $49 \%$ & & & & & & & & & 50 & \\
\hline Total & 6 & 9 & 5 & 1 & 0 & 0 & 0 & 0 & 2 & 5 & 13 & 9 \\
\hline
\end{tabular}

Fuente: INM, Consejo Insular de Aguas, Marzol, 1988, y Máyer 2003.

- episodios muy graves.

episodios graves.

detectar las sequías y la escala espacial empleada. En Canarias, además, se añade la diversidad territorial del archipiélago al ser un espacio insular con un relieve muy complejo y de gran entidad. En cualquier caso, son fenómenos ya analizados exhaustivamente, con especial referencia a la segunda mitad del siglo XX, por Marzol (1988, 2001a y 2001b) que explica la dificultad que supone acotar los episodios secos al emplear multitud de criterios de clasificación con resultados sensiblemente diferen- 
Figura 3. Situación sinóptica de precipitaciones intensas (izquierda) y de sequías (derecha) en Canarias.
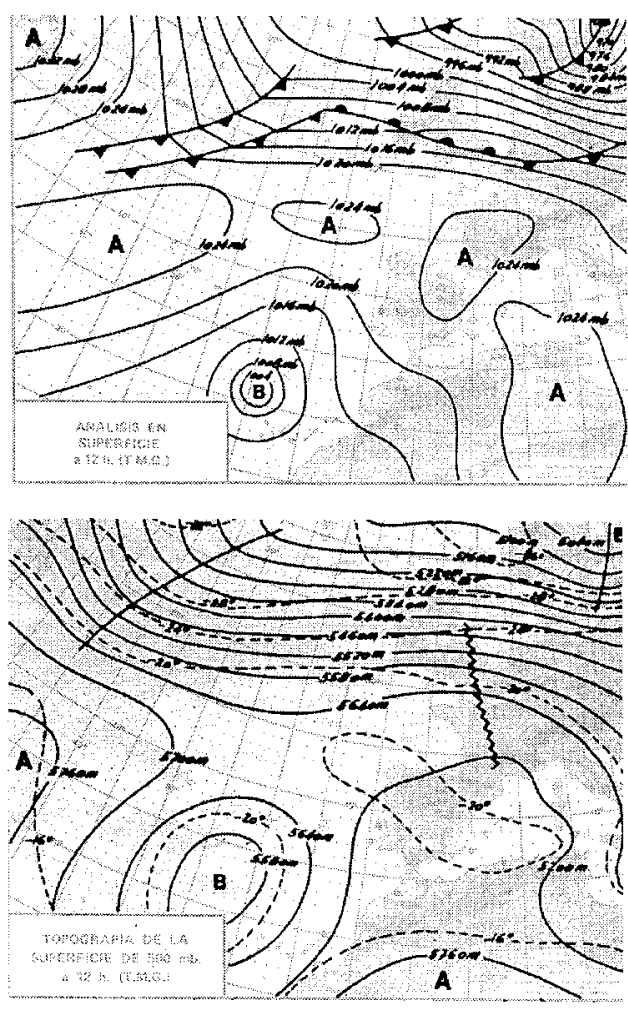
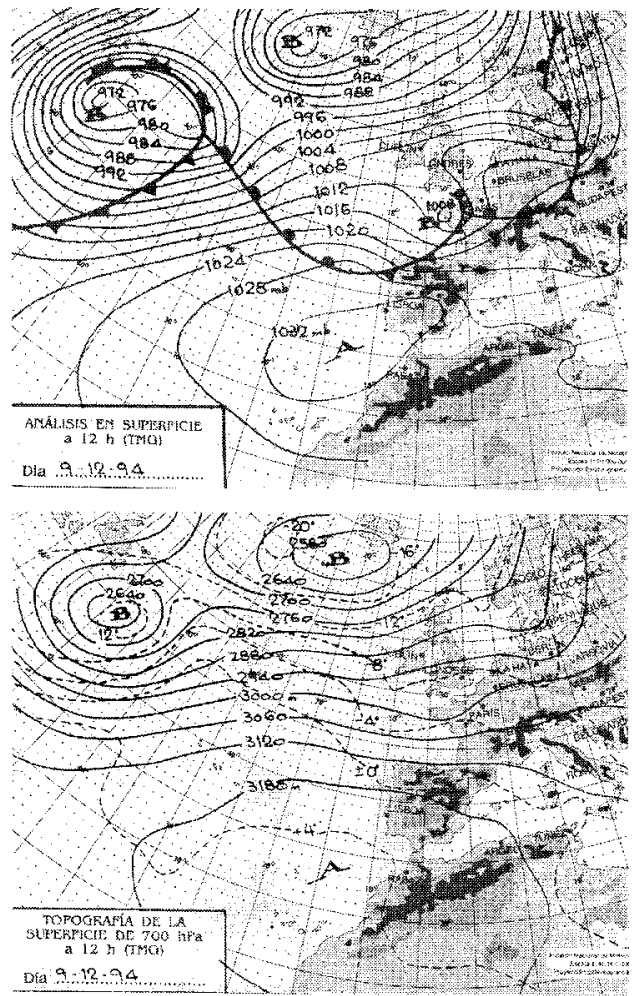

Fuente: INM.

tes. El más reciente de éstos consiste en considerar un episodio con déficit de agua aquel en el que tres meses consecutivos, como mínimo, la precipitación es inferior al $60 \%$ de la precipitación normal (Marzol, 2001b).

En cuanto a las sequías históricas son aún de más difícil detección no sólo por la falta de datos sino también por su discurrir lento, a diferencia de las riadas o las olas de calor de fuerte impacto social de forma casi instantánea. Sin embargo, son innumerables las referencias históricas y su estudio ha sido posible gracias a datos proxy. De esta manera, a través de las rogativas pro pluvia, se han detectado las secas más significativas de los siglos XVII (Romero y Máyer, 2002) y XVIII (Hernández, 1990), aunque en espacios distintos, Gran Canaria en el primer caso y Tenerife en el segundo. Resulta evidente la relevancia de estos fenómenos que constituyen un rasgo más del clima canario (cuadro 4). Analizando estos datos podemos llegar a la con- 
Cuadro 4. Sequías en Canarias en los siglos XVIII, XVIII y segunda mitad del XX.

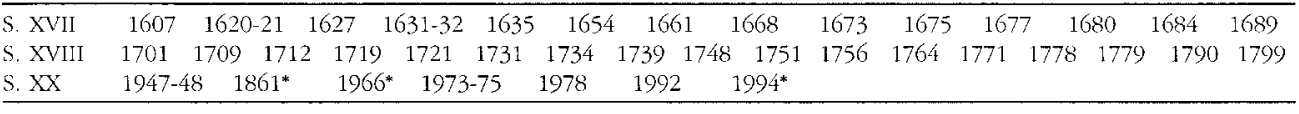

* Sequías más severas entre 1947 y 2000.

Siglo XVIII: Hernández, 1990. Siglo XVII: Romero y Máyer. Siglo XX: Marzol, 2001a y 2001b.

clusión de que hay en torno a quince sequías cada siglo. Éstas han tenido gravísimos efectos en la principal actividad de las islas, la agricultura. Sin embargo, en la actualidad la dependencia económica de este sector ha disminuido drásticamente y los sistemas de desalación de agua a gran escala han reducido sensiblemente la vulnerabilidad frente a estos procesos.

Sin embargo si entendemos la vulnerabilidad de una manera más amplia, habría que plantearse si es sostenible un sistema con una alta dependencia energética exterior y con consumos per cápita de 260 litros/día para la población local y de 320 litros/día para los turistas (Marzol, 2003), consumos que, además, crecen año tras año.

Como ejemplo de periodo seco podemos destacar la sequía de 1994 al ser, probablemente, la más intensa descle que se registran datos meteorológicos, como lo pone de manifiesto el mínimo pluviométrico de Izaña, la serie más larga con la que cuenta el archipiélago (desde 1916). En este observatorio apenas se alcanzaron 100 $\mathrm{mm}$, es decir aproximadamente un 20\% del valor medio y catorce veces menos que el máximo registrado en 1953. Al mismo tiempo se corresponde con un periodo muy seco también en la Península Ibérica porque el origen es el mismo: una situación de bloqueo anticiclónico. Asimismo, se observa la excepcionalidad en los años 50 como periodo extraordinariamente lluvioso y una ausencia general de periodos secos. Tampoco el cambio climático parece ser el responsable de las secas pluviométricas en Canarias, puesto que no es posible afirmar que en el archipiélago llueva menos en la actualidad que hace unas décadas (Marzol, 2001a).

La génesis de las sequías en Canarias se relaciona directamente con la instalación de un sector de altas presiones en las cercanías del archipiélago que engloba bajo su radio de acción a toda la región (figura 3). Si tomamos como referencia las sequías de principios de los 90 podemos observar un anticiclón de bloqueo en toda Europa suroccidental que, además, implica el establecimiento de flujos de componente Este sobre las islas, lo que se traduce en advecciones saharianas con aire seco y turbio por la presencia de polvo en suspensión. Estas situaciones suelen ser muy persistentes y pueden mantenerse durante semanas, precisamente en el invierno, la época de lluvias en Canarias y buena parte de la Península Ibérica. El hecho de que las precipitaciones se concentren en muy pocas borrascas hace que se produzca una gran diferencia interanual en la cantidad de lluvia, como indica el índice de disparidad consecutiva ya señalado. 


\subsection{Los temporales de viento}

Aunque es un fenómeno mucho menos estudiado que la precipitación o las olas de calor y tampoco existen análisis históricos, el viento supone un riesgo de primera magnitud que también ha generado graves daños en el archipiélago. Su frecuencia, como amenaza, es muy irregular y las rachas máximas se acercan a las registradas en el Cantábrico o la costa catalana, en especial después del paso por las islas de la tormenta tropical Delta en noviembre de 2005 (cuadro 5).

Cuadro 5. Velocidades máximas de viento alcanzadas en la red de observatorios principal de Canarias $(\mathrm{km} / \mathrm{h})$.

\begin{tabular}{|c|c|c|c|c|c|c|c|c|c|}
\hline Estación & E1 Hierro* & Izaña & La Palma* & Tenerife S & S.*'Tenerife N.* & Ianzarote* & Fuertev.* & S/C Tener. & G. Canaria* \\
\hline $\mathrm{Km} / \mathrm{h}$ & $136^{* *}$ & $248^{* *}$ & $152^{* *}$ & $134^{* *}$ & $147^{* * *}$ & $132^{* *}$ & $120^{* * *}$ & $162+$ & $113^{* *}$ \\
\hline
\end{tabular}

"Aeropuertos. "Novienbre de 2005. +Diciembre de 1975. Fuente: INM

Por regla general los principales temporales se producen con la llegada de borrascas atlánticas que dan lugar a fuertes vientos del cuarto cuadrante. Sin embargo son especialmente peligrosos los de dirección Sur puesto que la mayor parte de las infraestructuras no están preparadas para soportar vientos intensos no habituales del segundo o tercer cuadrantes. Aunque en Canarias los datos proceden de muy pocos observatorios, presentan series muy cortas y, en algunos casos, con lagunas importantes que impiden un estudio profundo de este elemento, los registros señalan hasta el momento que las islas han superado, en general, los $120 \mathrm{~km} / \mathrm{h}$. Sin embargo, es sabido que la configuración de la costa o de la topografía ocasiona un aumento en la velocidad del flujo, de manera que el relieve, como ocurría con la precipitación, posee un papel crucial en la peligrosidad de este elemento. Las montañas canarias generan efectos aceleradores como es el caso de las ondas de montaña o los vientos catabáticos que, dependiendo de la dirección originaria, asolan las vertientes cle sotavento. Así, determinados sectores costeros y de cierta altitud, las llamadas medianías, alcanzan los $150 \mathrm{~km} / \mathrm{h}$. y el caso más extremo lo representa Izaña, a $2367 \mathrm{~m}$ de altitud, con el record a escala nacional, habiendo superado en varias ocasiones los 200 $\mathrm{km} / \mathrm{h}$. Aún con la patente falta de datos, es evidente el registro de episodios de viento muy intenso (cuadro 6) con efectos muy graves especialmente en la agricultura, pero también con víctimas mortales como es el caso de Delta.

Los dos episodios de consecuencias más catastróficas para las islas en los últimos años han sido el temporal de enero de 1999 con vientos del segundo cuadrante de hasta $90 \mathrm{~km} / \mathrm{h}$ y daños estimados en 156 millones de euros (Criado y Dorta, 2003) y Delta que originó una víctima mortal y pérdidas aún por determinar. En el primer 
Cuadro 6. Datos más destacados de algunos de los temporales de viento más recientes y de peores consecuencias en Canarias*.

\begin{tabular}{|c|c|c|c|c|c|}
\hline Fecha & Vel. mäx. & Observatorio & Fecha & Vel mäx. & Observatorio \\
\hline $22 / 3 / 1960$ & $122 \mathrm{~km} / \mathrm{h}$ & Aeropuerto Los Rodeos & $12 / 02 / 1989$ & $197 \mathrm{~km} / \mathrm{h}$ & Izaña \\
\hline \multirow[t]{2}{*}{$8 / 04 / 1968$} & 108 & Puerto del Rosario- & & & Aeropuerto \\
\hline & & Los Estancos & $18 / 01 / 1991$ & 133 & Los Rodeos \\
\hline \multirow[t]{2}{*}{$3 / 01 / 1970$} & 94 & Aeropuerto & & & \\
\hline & & Gran Canaria & $17-18 / 01 / 1994$ & 201 & Izaña \\
\hline $7 / 03 / 1974$ & 144 & Mazo-Aeropuerto & $21 / 12 / 1996$ & 135 & Mazo-Aeropuerto \\
\hline \multirow[t]{2}{*}{$14 / 12 / 1975$} & $216 / 162$ & Izaña/Santa Cruz & & & \\
\hline & & de Tenerife & $7 / 01 / 1999$ & 89 & Varias \\
\hline $4 / 2 / 1976$ & 128 & Santa Cruz de Tenerife & $15 / 04 / 00$ & 102 & Mazo-Aeropuerto \\
\hline $7 / 01 / 1977$ & 104 & Santa Cruz de Tenerife & $21 / 22 / \mathrm{dic} / 00$ & 113 & Mazo-Aeropuerto \\
\hline $6 / 1 / 1979$ & 200 & Izaña & $19-20 / 02 / 2004$ & 113 & Mazo-Aeropuerto \\
\hline \multirow[t]{2}{*}{$15 / 12 / 1984$} & 98 & Acropuerto Tenerife & & & Aerop. Mazo \\
\hline & & Sur & $24-27 / 02 / 2005$ & 121 & y Los Cangrejos \\
\hline
\end{tabular}

*De forma muy habitual la velocidad máxima se alcanza en Izaña, sin embargo sólo citamos esta estación cuanclo ha llegado o ha estado en torno a $\operatorname{los} 200 \mathrm{~km} / \mathrm{h}$

Fuente: INM.

caso, el principal peligro se originó como consecuencia de la dirección del viento puesto que, como hemos señalado, las infraestructuras no están adaptadas para soportar vientos fuertes de componente Sureste, de ahí los graves daños. El segundo caso, la tormenta tropical Delta, fenómeno inédito en Canarias desde que se cuenta con datos meteorológicos, ha supuesto records en la mayor parte de la red de anemómetros de las islas (cuadro 5) -velocidades por encima de los $150 \mathrm{~km} / \mathrm{h}$ en algunos sectores y hasta $250 \mathrm{~km} / \mathrm{h}$ en Izaña- y los efectos se han dejado sentir en todas las islas. Sin embargo, ha habido otros temporales con intensidades similares como el diciembre de 1975, que marcó el viento máximo en Santa Cruz de Tenerife, $162 \mathrm{~km} / \mathrm{h}$. Además, con la información histórica disponible, no descartamos otros eventos de similares características como el ya citado de 1826, que no sólo se caracterizó por la intensidad de la lluvia sino también por la extraordinaria velocidad alcanzada por el viento, evaluada en función de los efectos producidos.

En cualquier caso, la aparición de tormentas tropicales en Canarias, como Delta, supone algo desconocido al menos desde que se registran datos de viento en las islas y su posible repetición constituye una inquietante amenaza aún no bien evaluada.

Al mismo tiempo, una de las principales consecuencias de los episodios de viento intenso son los temporales marinos, ampliamente estudiados (Yanes et al., 2006), como los que se originaron en enero de 1999 o abril de 2003 y con graves efectos en playas y puertos de las islas. 
La situación sinóptica que origina fuertes vientos en el archipiélago se traduce en la llegada de borrascas profundas -en el contexto climático canario- (figura 4). Sin embargo, al analizar los datos también nos encontramos con una cierta variedad de situaciones. No sólo Delta no sigue ese modelo, también determinadas entradas de aire tropical continental como consecuencia de la instalación de bajas presiones en las cercanías del archipiélago, como enero de 1999, que se convierten en núcleos de presión que literalmente aspiran el aire situado sobre el desierto dando lugar a vientos muy violentos y racheados, sobre todo en las laderas Norte y Oeste, las situadas a sotavento.

Figura 4. Situación sinóptica de vientos fuertes sobre Canarias.
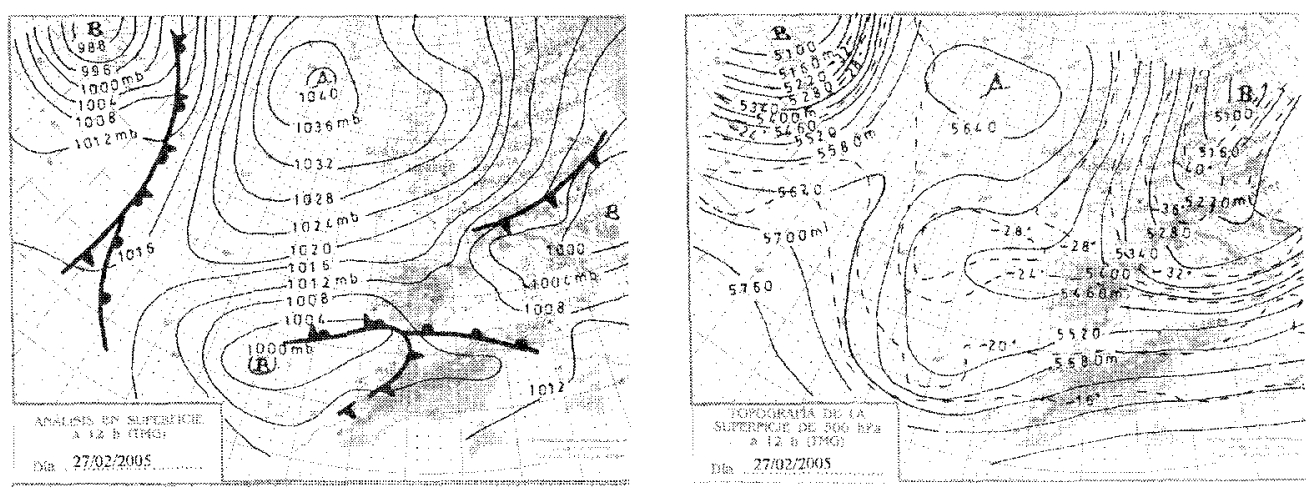

Fuente: INM.

\subsection{Los riesgos derivados de las advecciones de aire sahariano}

La llegada a las islas de masas de aire sahariano es muy habitual, cifrándose su frecuencia en un 22\% de las fechas del año (Dorta et al., 2005). Éstáls son responsables de dos nuevos peligros de origen climático: las olas de calor y las entradas masivas de polvo en suspensión. Ambas tienen importantes repercusiones ambientales, económicas y en la salud de la población. El desplazamiento de este aire tropical continental se produce en cualquier época del año, aunque es más frecuente en invierno y presenta un mínimo marcado en primavera (Dorta et al., 2003). Sin embargo, sus rasgos termohigrométricos -altas temperaturas y baja humedad relativa- son más evidentes en verano. 


\subsubsection{Las olas de calor}

El calentamiento del desierto es mucho más intenso en los meses más cálidos por lo que las olas de calor, entendidas como aumentos pronunciados de temperatura, se producen sobre todo desde mediados de la primavera hasta mediados del otoño. Los valores térmicos extremos, según los datos de los observatorios canarios, muestran temperaturas máximas absolutas que, a escala nacional, sólo se superan en el interior de Andalucía, Extremadura y Murcia. Con series relativamente cortas se han sobrepasado los $44^{\circ} \mathrm{C}$ en varias estaciones de la red principal y los $45^{\circ} \mathrm{C}$ en algunas de la secundaria (Dorta, 1991) (cuadro 7). Además, la diferencia entre la media de las máximas y los valores absolutos muestran una virulencia, en general, superior a los observatorios de la mitad sur peninsular, lo que supone un mayor impacto de cara a la población y, por consiguiente, en los riesgos. En los sectores de medianías, son normales aumentos en 24 horas superiores a los $10^{\circ} \mathrm{C}$, llegando en los casos extremos a rozar los $20^{\circ} \mathrm{C}$ (Dorta, 1989). Además los altos valores nocturnos son un rasgo en el que Canarias también representa intensidades máximas a escala nacional. Temperaturas por encima de $\operatorname{los} 26-28^{\circ} \mathrm{C}$ se producen casi todos los años y en algunos casos no se desciende en toda la noche de $29-30^{\circ} \mathrm{C}$. Asimismo, la llegada de masas de aire sahariano da lugar a caídas extraordinarias en los valores de la humedad relativa, que pueden situarse por debajo del 15\% (Dorta, 1991) en un medio, no lo olvidemos, eminentemente oceánico.

Sus efectos son evidentes en la propagación del fuego en los bosques canarios casi el 95\% de las hectáreas han ardido bajo situaciones de advección sahariana (Dorta, 2001)-, en la productividad agraria y también en la salud de la población. Las últimas olas de calor registradas en Canarias han sido especialmente virulentas, destacando la de julio de 2004 , originando la muerte de 13 personas.

Aún a pesar de la dificultad en la definición de ola de calor, como lo demuestra incluso el reciente Plan Nacional de Predicción y Vigilancia de Meteorología Adversa (Meteoalerta) del INM, al considerar umbrales diferentes para las dos provincias canarias, las altas temperaturas suponen algo habitual en el clima del archipiélago, como ha quedado de manifiesto. Al igual que en el resto del país y, en general en el mundo occidental, la mayor preocupación de las autoridades sanitarias por los efectos en la salud de la población ha hecho que estos eventos se estén convirtiendo en uno de los riesgos climáticos que ocasiona mayor número de víctimas, seguramente no tanto por su aumento como por evaluar de manera mucho más efectiva los efectos del calor sobre las personas. De hecho, en las islas en el siglo XXI, ya se han contabilizado más muertos por calor que por cualquier otro fenómeno meteorológico - 16 víctimas en los episodios de 2004 y $2006-$.

Probablemente las dos olas de calor recientes más destacadas sean las de agosto de 1990 y julio de 2004, siendo también muy intensas las de julio de 1952 y agosto 
Cuadro 7. Principales olas de calor en Canarias (1950-2004)

\begin{tabular}{|c|c|c|}
\hline Episodio & Valores destacados ${ }^{\circ} \mathrm{C}$ & Observatorio \\
\hline Jul 1952 & $44,2 / 42,6$ & Aeropuerto Gran Canaria/Santa Cruz de Tenerife \\
\hline Jul 1953 & $48,0 / 45,0$ & Arrecife*/Inagua* \\
\hline Ago-sep 1953 & $46,0 / 41,0$ & Los llanos de Aridane/Inagua \\
\hline Jul 1957 & 40,0 & Aeropuerto Los Rodeos \\
\hline Jul-ago 1958 & 40,6 & Aeropuerto Los Rodeos \\
\hline Jul 1961 & 40,4 & Santa Cruz de Tenerife \\
\hline Ago 62 & 43,0 & Puerto del Rosario-Los Estancos \\
\hline Ago 66 & $47,0 / 41,2$ & Guargacho*/Aeropuerto Los Rodeos \\
\hline Jul-1967 & $44,0 / 39,6$ & $\begin{array}{l}\text { Puerto del Rosario-Los Estancos/Aeropuerto Gran } \\
\text { Canaria }\end{array}$ \\
\hline Ago 1974 & 41,5 & Valleseco ${ }^{*}$ \\
\hline Jul 1975 & $43,0,40,5$ & Aeropuerto Fuerteventura/Valleseco* \\
\hline Ago 1976 & $46,0 / 44,0$ & Tacoronte*/Agaete* \\
\hline Jul 1978 & $42,0 / 40,0$ & Garimba*/Inagua \\
\hline Jul 1979 & 40,6 & Santa Cruz de Tenerife \\
\hline Ago 1980 & $43,6 / 40,5$ & Lanzarote Aeropuerto/Aeropuerto Tenerife Sur \\
\hline Jul 1982 & $42,6 / 40,4$ & Aeropuerto Tenerife Sur/Aeropuerto Los Rodeos \\
\hline Sep 1983 & 40,0 & Varias \\
\hline Ago 1985 & 41,5 & Las Tricias* \\
\hline Sep 1986 & $41,8 / 40,5$ & Aeropuerto Tenerife Sur/ Lanzarote Aeropuerto \\
\hline Sep 1987 & $43,0 / 39,0$ & El Carrizal*/ Aeropuerto Gran Canaria \\
\hline Jul 1988 & 44,0 & Añavingo* ${ }^{*}$ \\
\hline Ago 1988 & $44,3 / 41,0$ & Aeropuerto Tenerife Sur/Aeropuerto Fuerteventura \\
\hline Ago 1990 & 41,3 & Añavingo* \\
\hline Jul 1994 & $41,1 / 41,3$ & Aeropuerto Los Rodeos/Lanzarote Aeropuerto \\
\hline Jul 2004 & 42,9 & Aeropuerto Lanzarote \\
\hline
\end{tabular}

Fuente: INM.

de 1966, 1976 y 1988. La primera destacó además de por las altas temperaturas por las bajísimos porcentajes de humedad relativa. El verano de 2004 ha sido uno de los más calidos desde que se cuenta con datos. En realidad se produjo la sucesión de tres olas de calor, la primera a principios de julio, una segunda a finales del mismo mes y la tercera en los últimos días de agosto. La de mayor virulencia se registró entre el 23 y 29 de julio y se caracterizó, sobre todo por las elevadas temperaturas mínimas que rebasaron $\operatorname{los} 30^{\circ} \mathrm{C}$ en algunos observatorios y fueron las principales responsables de las muertes ocasionadas. En Santa Cruz de Tenerife no se bajó en ningún momento de los $26^{\circ} \mathrm{C}$ entre los días 25 y 29 .

En todos los casos (cuadro 7), la situación sinóptica se caracteriza por una depresión sobre el Sáhara que engloba a las islas y establece flujos directamente desde el 
desierto (figura 5) con un descenso muy pronunciado en la altitud de la inversión térmica de subsidencia propia de los vientos alisios, lo que hace que normalmente los efectos en el cambio termohigrométrico sean mayores a altitudes medias-medianíasque a nivel del mar.

\subsubsection{Entradas masivas de polvo sahariano}

Darwin en 1832, a su llegada al puerto de Santa Cruz de Tenerife, describe una situación de intensa calima; otra referencia ampliamente descrita es la de febrero de 1898 y la presencia de grandes cantidades de polvo en suspensión aparece reflejada también en multitud de textos antiguos. Este tipo de fenómenos atmosféricos son, por tanto, muy recurrentes en las islas (enero de 1983, febrero de 1994, marzo de1995, etc.), aunque los eventos de mayor grado sólo se producen de una a tres veces anualmente (cuadro 8), constituyendo una amenaza más en el clima canario.

Figura 5. Situaciones sinópticas de ola de calor (izquierda) y de entrada masiva de material litogénico (derecha).
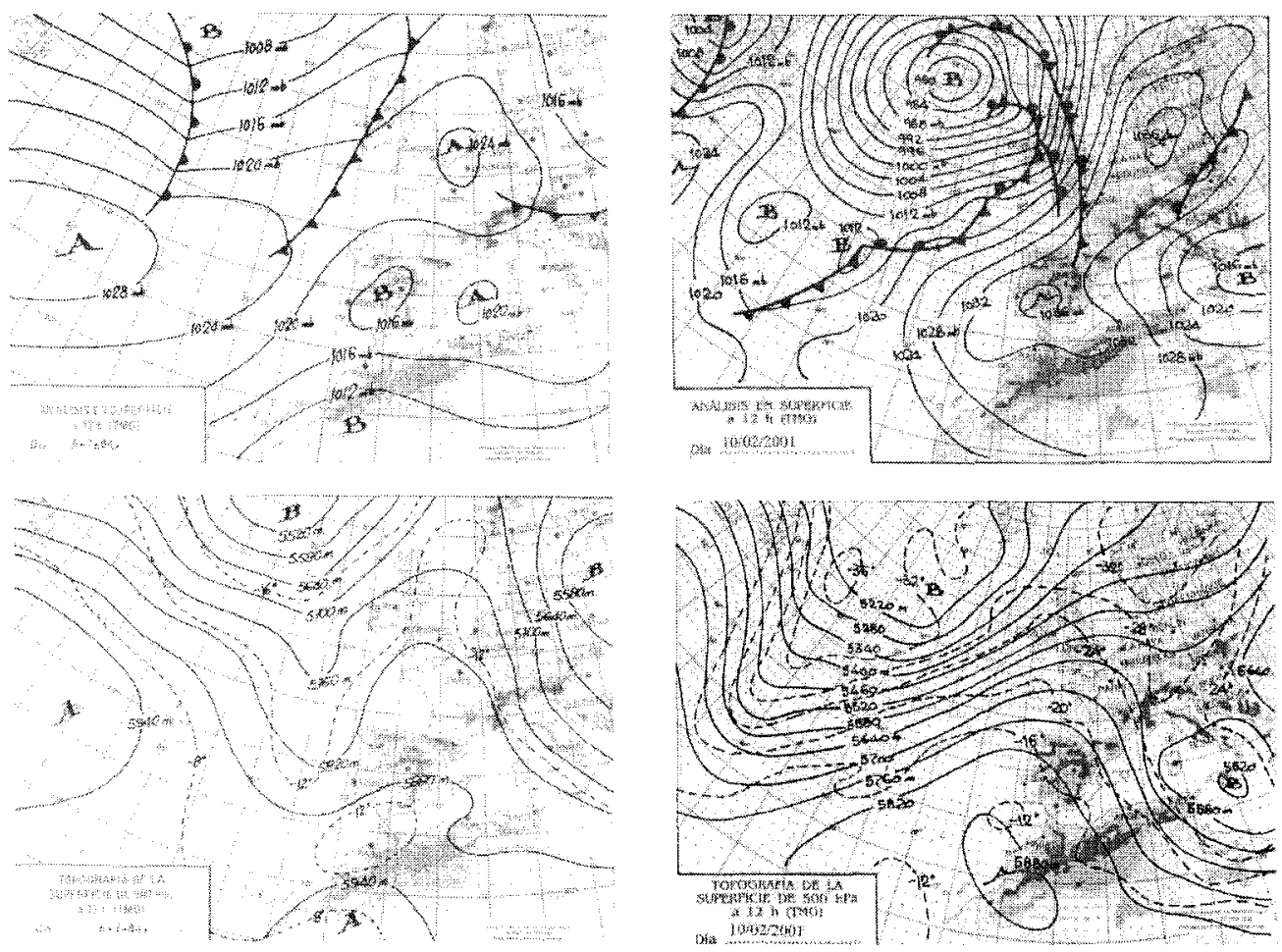
Cuadro 8. Algunas de las entradas masivas de polvo sahariano de mayor intensidad en los últimos años en Gran Canaria (1998-2004)*.

\begin{tabular}{cccc}
\hline Fecha & Cantidad máxima diaria $(g / m 3)$ & Fecha & Cantidad máxima diaria (_g/m3) \\
\hline Feb 1998 & 1312,8 & Abr 2002 & 474,8 \\
Jun 1998 & 416,3 & Oct 2002 & 401,9 \\
Oct 1998 & 1143,4 & Mar 2003 & 492,9 \\
Feb 1999 & 1003,8 & Feb 2004 & $2020,4+$ \\
Dic 2001 & 510,5 & Mar 2004 & $2295,5+$ \\
Ene 2002 & 1862,0 & Ago 2004 & $467,3+$ \\
\hline
\end{tabular}

Fuente: Dpto de Química. Universidad de Las Palmas de Gran Canaria

* Sin datos entre marzo de 1999 y octubre cle 2001

Los datos son recogidos a 1930 m.s.n.m. excepto + que son a 269 m.s.n.m.

Su mayor frecuencia en las capas bajas de la troposfera se produce durante el invierno y en los eventos más importantes se han superado los $500 \mu \mathrm{g} / \mathrm{m}^{3}$, llegando a extremos de más de $1000 \mu \mathrm{g} / \mathrm{m}^{3}$ (Dorta et al., 2005). En estos casos la intensidad llega a ser tal que la reducción de visibilidad es muy significativa. Ya han sido analizados exhaustivamente algunos de los episodios más recientes, como el ocurrido en abril de 2002 (Dorta et al, 2002) y en la actualidad se realizan diversas investigaciones (www.calimacanaria.org) que están midiendo las cantidades y la composición química del material litogénico. Su estudio se centra en el origen y desplazamiento de las nubes de polvo con el empleo de modelos como el HYSPLIT de la NOAA para el análisis de las retratrayectorias de las masas de aire. Las primeras conclusiones señalan la importancia de los aportes, cifrados en unos 2 millones de toneladas anuales de material particulado para el área de Canarias (Torres-Padrón, 2002).

Sus repercusiones son muy diversas, aunque no están aún bien evaluadas. La baja visibilidad, en los casos más extremos por debajo de los 200 metros, repercute en las comunicaciones aéreas incluso con el cierre de los aeropuertos, aunque sus principales efectos tienen que ver con la salud de la población, al existir una estrecha relación entre el material particulado y el aumento ya constatado de algunas enfermedades de tipo respiratorio (García et al., 2001), causando efectos negativos sobre todo las partículas de menor tamaño - por debajo de 10 micras (PM10)-, muy abundantes en estas intrusiones saharianas (Gelado et al., 2003) y de especial relevancia en la legislación medioambiental europea sobre Calidad del Aire (Directiva 1999/30/CE).

Por último hay que señalar que las advecciones de aire sahariano han supuesto la llegada de plagas de langosta, hoy en día muy controladas pero que han tenido históricamente efectos gravísimos en el campo canario.

La situación sinóptica tipo (figura 5) se caracteriza por la presencia de un gran sector de altas presiones sobre el SW europeo o NW de África que por su flanco meri- 
dional envía aire de origen sahariano hasta el archipiélago; o bien una depresión, en general poco profunda, en las cercanías de las islas que generan un flujo de aire cargado de aerosoles hacia el núcleo. La presencia de tormentas de arena sobre el desierto aumenta la cantidad de polvo que se inyecta a la baja y media troposfera, lo que facilita el transporte a larga distancia y la intensidad de las nubes de material litogénico sobre las islas. En ocasiones esas depresiones generan la deposición de las partículas saharianas por medio de lluvias intensas, con referencias para febrero de 1920 , febrero de 1989 o enero de 1999 (Criado y Dorta, 2003).

\section{3. ¿Aumenta la vulnerabildad?}

Toda la exposición realizada muestra, con datos objetivos, la frecuencia aproximada de las amenazas de origen climático, sus umbrales de peligro, sus valores extremos y sus principales efectos (cuadro 10). Además se ha verificado que han sido una constante en la historia del archipiélago, siendo incuestionable que los extremos pluviométricos, o térmicos, o las entradas masivas de polvo en suspensión, o los fuertes vientos han existido siempre. Sin embargo el grado de exposición ha aumentado y la sociedad canaria es más vulnerable como lo indican las cifras económicas y el elevado número de víctimas mortales de los últimos años.

Achacar todos los recientes acontecimientos meteorológicos al cambio climático es, en cierta medida, falsear la realidad. Resulta evidente que la velocidad en el incremento de la vulnerabilidad es superior a la del calentamiento global, y los mayores efectos de los fenómenos meteorológicos adversos no tienen uná componente climática sino fundamentalmente antropogénica. Sí es cierto, sin embargo, que en los últimos años se han producido algunos fenómenos meteorológicos de extraordinaria intensidad y de origen insólito como Delta o precipitaciones intensas en pleno mes de agosto, por lo que el cambio climático, en cualquier caso, sólo puede aumentar aún más el grado de vulnerabilidad de la sociedad canaria al incrementar la virulencia y la frecuencia de las amenazas.

Una de las causas fundamentales en el aumento de la vulnerabilidad tiene su origen último en el acelerado crecimiento demográfico que ha sufrido Canarias en los últimos 25 años, pasando de una densidad de población de $183 \mathrm{hab} / \mathrm{km}^{2}$ en 1981 a 263 en 2005. Tanto la población residente como el número de turistas no han dejado de aumentar a ritmos vertiginosos, siempre entre las comunidades de mayor crecimiento de nuestro país. Todo ello acompañado de un aumento generalizado de múl- 


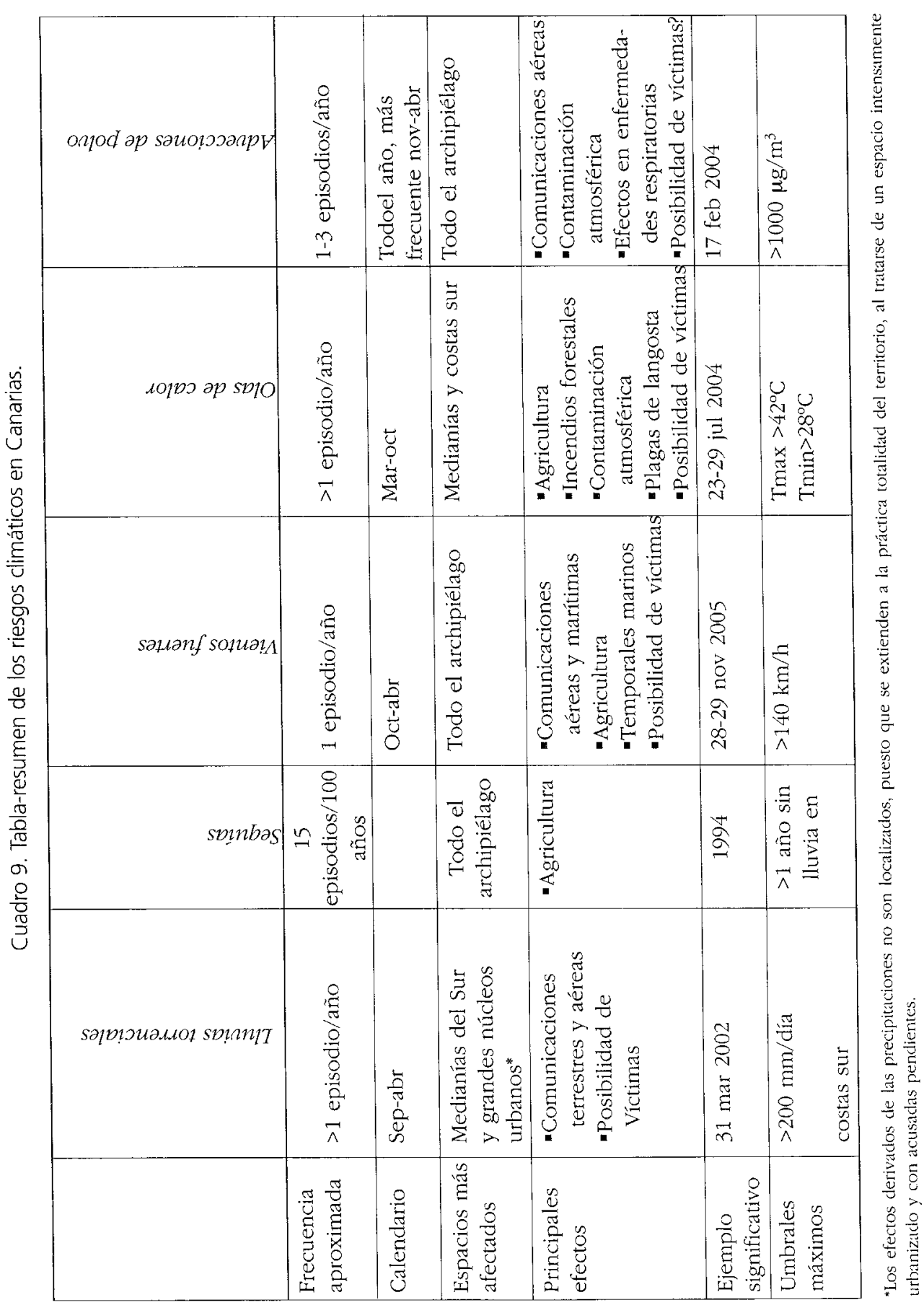


tiples infraestructuras, en especial de comunicación y de alojamiento turístico ${ }^{3}$, llegando en la actualidad a 400.000 camas oficiales, el $70 \%$ de las cuales concentradas en sectores muy concretos de las dos islas centrales. Ese aumento demográfico, superior el $45 \%$ entre 1981 y 2005, se ha rebasado en islas como Lanzarote y Fuerteventura con más de un $150 \%$ y en los principales municipios turísticos $-235 \%$ en Arona (Tenerife)-. Las dos islas más pobladas poseen una densidad que se sitúa entre $400 \mathrm{hab} / \mathrm{km}^{2}$ en Tenerife y los $500 \mathrm{hab} / \mathrm{km}^{2}$ en Gran Canaria ${ }^{4}$. El crecimiento poblacional casi triplica al del total del país, mientras que las proyecciones demográficas prevén rozar los 2,5 millones de habitantes en $2019^{5}$ y superar en densidad de población al País Vasco en muy poco tiempo, quedando únicamente por detrás de Madrid.

El aumento de la vulnerabilidad se hace patente cuando se observa que los problemas que ocasiona la lluvia se multiplican y cuando los umbrales necesarios para que estos se produzcan descienden año tras año. Según señala Marzol (2002), el crecimiento de la ciudad de Santa Cruz de Tenerife ha desembocado en que el riesgo se alcance con volúmenes de precipitación de menos de $40 \mathrm{~mm}$ en doce horas, a la vez que se produce un aumento del número de inundaciones en el siglo XX. Asimismo, en Las Palmas de Gran Canaria a partir de 1960 aparecen daños con cantidades de lluvia de sólo $30 \mathrm{~mm}$ (Máyer, 2003b) y se detecta una reducción progresiva del umbral a partir del cual comienzan a darse problemas en la ciudad (Máyer, 2001). Las zonas turísticas se convierten en un caos cuando la precipitación supone sólo algunas decenas de milímetros, como ocurrió en diciembre de 2002 con algo más de 60 $\mathrm{mm}$ en el sur de Tenerife y Gran Canaria.

Los rasgos climáticos y geomorfológicos así como el tipo de construcción en laderas e incluso en cauces o desembocaduras de barrancos hacen que exista un alto riesgo de avenida en gran parte de los núcleos urbanos y turísticos, muchos de ellos de nueva o de reciente creación, aunque el problema se extiende ya a la mayor parte de los núcleos de población. En general se asume el riesgo, pero eso hace que los umbrales de peligro sean cada vez menores. Como señalan Moral y Pita (2002, p. 78):

\footnotetext{
${ }^{3}$ Se trata de una aproximación a los temporales de lluvia más importantes acaecidos en lás islas. Existen otros relevantes en cuanto a efectos -con volúmenes de precipitación relativamente escasos- que no aparecen representados puesto que la lista sería interminable. Es el caso del 4 de abril de 1997 , diciembre de 2002 o el más reciente del 1 noviembre de 2006. Todo lo cual da iclea de lo difícil que resulta lał selección de las fechas más significativas.

${ }^{4}$ Según el Instituto Canario de Estadística, el 1 de enero de 2005, Canarias contaba con 1.968.280 habitantes, durante este año se rebasará la cifra de los 2 millones de habitantes

${ }^{5}$ En realidad en una aproximación al territorio la presión demográfica es aún mayor al tratarse de islas de acusadas pendientes. En Tenerife, por ejemplo, si se descuenta la superficie protegida, las pendientes de más del $30 \%$ y la altitud superior a los $1200 \mathrm{~m}$, donde la población es testimonial, la clensidad supera ligeramente los $1000 \mathrm{Hab} / \mathrm{km}^{2}$ (Consejo Insular de Aguas, 2005, 9).
} 
"cada fase de crecimiento social y económico se ha acompañado del surgimiento de nuevos riesgos que han sido la condición de posibilidad del propio progreso". El proceso se convierte en interminable, "en caracol", si la ocupación del espacio continúa sin apenas control, y Canarias representa uno de los mejores ejemplos de ese proceso.

En esta línea, el Consejo Insular de Aguas del Cabildo Insular de Tenerife, utilizando Log-Pearson III -que parece que se ajusta mejor a la realidad pluviométrica de las islas que Gumbel-, ha estimado que prácticamente la totalidad de la isla de Tenerife, incluidos los grandes núcleos turísticos, posee periodos de retorno de más de $200 \mathrm{~mm}$ para 500 años. Ese valor no se ha alcanzado aún en buena parte de la isla, pero con registros de sólo unas decenas de milimetros se producen víctimas mortales en pleno siglo XXI. En Gran Canaria, en sectores de similar orientación y topografía, con precipitaciones medias anuales de menos de $120 \mathrm{~mm}$ ya se han superado los $200 \mathrm{~mm}$-201,3 mm en Maspalomas en noviembre de 1950 (Máyer et al., 1999)-, pero antes del boom turístico, es decir, sin una sola plaza alojativa. Hoy se encuentra el 90\% de las camas turísticas de la isla -más de 130.000-, además de la población residente. Por todo ello es muy probable, con el nivel de edificación actual, que precipitaciones similares o incluso sensiblemente inferiores ${ }^{6}$ ocasionen severos daños en las zonas vacacionales, daños para los que no están en absoluto preparados los núcleos urbanos dedicados al turismo. En este sentido, un aspecto importante es la vulnerabilidad económica no ya sólo derivada de los daños ocasionados en infraestructuras o equipamientos, sino también por los efectos en la pérdida de capacidad de atracción turística de las islas si no se cuenta con planes de riesgos completos y adecuados. No se debe olvidar que el clima representa, muy por encima de cualquier otro, el principal atractivo turístico de estas islas como lo demuestran las encuestas a los propios visitantes (Dorta, 2004). La percepción exterior de los rasgos climáticos del archipiélago es una de las principales bases sobre la que se fundamenta toda la explotación turística. Sucesos que den lugar a pérdida de vidas humanas o a daños severos en infraestructuras y equipamientos tendrían un impacto muy negativo en la definición de destino seguro. Como señala Gómez, "los estudios de prospectiva turística deben ir acompañados de estudios de sucesos extremos y de sus correspondientes planes de prevención de riesgos" (Gómez, 2005, p. 118).

En este contexto, pero también en la línea del resto de las autonomías, han surgido toda una serie de disposiciones relacionadas con las emergencias y la protección

\footnotetext{
${ }^{6}$ Así, según el Instituto Canario de Estadística (ISTAC), la población en los próximos 14 anoos creecrá algo más de un 26\% (2004-2019).
} 
civil, como el PLATECA ${ }^{7}$, o el PEFMA ${ }^{8}$, este último en relación también con el propio INM y su recientemente instaurado METEOALERTA, todo ello con el objetivo de reducir los efectos catastróficos de los fenómenos meteorológicos adversos. Además, la legislación canaria, por medio del decreto 35/1995 y el citado PLATECA insta a los ayuntamientos a la elaboración de planes de emergencia y mapas de riesgo como instrumentos de planeamiento. Y es ahí, en la prevención y en la planificación donde continúa habiendo una considerable falta de previsión, en la ordenación de un territorio absolutamente limitado y totalmente desbordado en cuanto a la explotación de sus recursos, como lo demuestra el hecho de que sea casi testimonial el número de municipios que cuentan con esa cartografía específica y los planes de emergencia concluidos: 5 de un total de 87.

Resulta urgente realizar una adecuada ordenación territorial, sería conveniente elaborar esos documentos de planificación, estimar caudales máximos con precipitaciones reales o aumentar los periodos de retorno. A la falta de fiabilidad de estos últimos para Canarias, como ha quedado de manifiesto por la elevada irregularidad interanual, se añade el hecho de que la red de pluviógrafos es muy deficiente en cuanto al número por la compleja orografía canaria y, sobre todo, en cuanto a la amplitud de las series teniendo en cuenta las enormes desviaciones típicas de los datos. Sería, por tanto, necesaria una red mucho más densa con el fin de conocer la intensidad real de la precipitación (parámetro obligado en el cálculo de los caudales de avenidas). La alta concentración temporal de la lluvia hace que la precipitación total en 24 horas no sea fiable como lo demuestra el hecho de que la mayor parte de los episodios de lluvias intensas apenas duran unas horas.

\section{Conclusiones}

- La imagen de un clima agradable y apacible no es del todo acorde con la entidad de los riesgos climáticos en Canarias, que son reales y que suponen una amenaza constante que aumenta a medida que crece la población residente y el número de turistas que visitan las islas.

- Las precipitaciones torrenciales, las intensas olas de calor, los vientos, las entradas masivas de polvo en suspensión no son algo nuevo. Aunque poco frecuentes, forman parte de los rasgos climáticos de las islas y no comienzan a producirse cuando la comunidad científica constata el calentamiento global. Todos ellos se han repetido, al menos, desde el siglo XVI hasta la actualidad.

\footnotetext{
${ }^{7}$ Valores entorno a los $100 \mathrm{~mm}$, que son los señalados para periodos cle retorno de 100 años.

8 plan Territorial de Emergencias de Protección Civil de la Comunidad Autónoma de Canarias, aprobado y publicada su actualización por Decreto 1/2005, de 18 de enero, B.O.C. n 154 , de 8 de agosto de 2005.
} 
- La catástrofe que supone la consecución del riesgo se hace evidente cuando constatamos los centenares de víctimas asociadas directamente al clima a lo largo de la historia. Pero no debemos hablar en pasado, ya ha habido decenas de muertos en el siglo XXI: tres en 2001, ocho en 2002, trece en 2004, dos en 2005 y tres en 2006.

- El relieve es un elemento decisivo en la distribución de los elementos climáticos y, de cara a los riesgos, sobre todo en la concentración temporal y espacial de la precipitación y en la aceleración de los flujos de aire. La configuración topográfica de las islas en la que predominan las pequeñas cuencas facilita las denominadas inundaciones relámpago. Es normal que el volumen de lluvia de un episodio iguale o, incluso, supere la media de los valores anuales, lo que da idea de esa concentración en el tiempo del fenómeno.

- Se trata de precipitaciones muy poco frecuentes, al ser muy puntuales en el espacio, lo que las hace más destructivas puesto que ni las infraestructuras, ni la población, están preparadas para afrontarlas. La concentración espacial y temporal de la lluvia en Canarias supone, por tanto, una amenaza severa, lo que unido a la alta vulnerabilidad crea situaciones de riesgo extremo.

- Es evidente que los datos ofrecidos muestran la alta probabilidad de precipitaciones torrenciales en casi cualquier punto de las islas. Sin embargo, los periodos de retorno no son eficaces para evaluar la probabilidad de ocurrencia del fenómeno tal y como se ha demostrado, por ejemplo, para las lluvias del 31 de marzo de 2002 en Santa Cruz de Tenerife.

- Asimismo, los desniveles topográficos generalizados dejan poco espacio llano o de baja pendiente, por lo que una parte importante de la población vive en áreas muy expuestas a fuertes escorrentías. El rápido incremento poblacional hace que la vulnerabilidad vaya en aumento en los sectores más poblados de las islas con umbrales de riesgo cada vez más bajos.

- De cara al sector turístico -doce millones de visitantes anuales-, ha quedado de manifiesto que es necesario un análisis exhaustivo de todas las facetas relacionadas con los riesgos climáticos: la propia amenaza (lluvia, calor, sequía, etc.), una planificación futura acorde con dichas amenazas y unos sistemas de emergencia adecuados al tipo y frecuencia de los fenómenos meteorológicos extremos.

- En esta línea, según señala el programa de acción de la Estrategia Internacional de Reducción de Desastres de las Naciones Unidas, la escala local juega un papel crucial. Sin embargo los planes urbanísticos no cuentan, en general, con estudios específicos de riesgos, ni siquiera de áreas inundables, aunque sí existe una legislación que exige mapas de riesgos y planes de emergencia. Legislación que no se cumple: un ejemplo, más del $90 \%$ de los ayuntamientos canarios no cuentan con los citados planes de emergencia.

- Por último, la planificación del territorio y la gestión de los eventos potencialmente catastróficos ha de tener en cuenta estos riesgos y la posibilidad de un incremento en su intensidad como consecuencia del cambio climático. 


\section{Bibliografía}

Ayala, F. J. (2002a): El sofisma de la imprevisibilidad de las inundaciones y la responsabilidad social de los expertos. Un análisis del caso español y sus alternativas. Boletín de la $A G E, 33$, p. 79-92.

Ayala, F.J. (2002b): Introducción a la matemática probabilística del riesgo. En AyalaCarcedo y Olcina (eds.) Riesgos Naturales. Madrid, Ariel Ciencia.

Ayala, J. y Olcina, J. (2002): Riesgos Naturales. Barcelona, Ariel Ciencia.

Criado, C. y Dorta, P. (2003): An unusual blood rain over canary islands (Spain). The storm of January 1999. Journal of Arid Environments, 55, p. 765-783.

Cola, L. (1986): Barrancos de Añazo. Santa Cruz de Tenerife, Excmo. Ayuntamiento de Santa Cruz de Tenerife.

Consejo Insular de Aguas (2005): Plan de Defensa frente a Avenidas (avance). Cabildo Insular de Tenerife.

Dávila M.P. y Romero, L.E. (1993): Precipitaciones máximas en Lanzarote. Régimen de intensidades y frecuencias. $V$ Jornadas de estudios sobre Lanzarote $y$ Fuerteventura. Tomo V, p. 54-72. Exmo. Cabildo Insular de Fuerteventura.

Dorta, P. (1989): Las olas de calor estivales en Tenerife y Gran Canaria. Memoria de Licenciatura. Universidad de La Laguna.

Dorta, P. (1991): Características climatológicas de las olas de calor estivales en Canarias. Alisios, 1, p. 7-20.

Dorta, P. (1995): Algunos efectos de las advecciones de aire cálido sahariano en Canarias. VI Coloquio Ibérico de Geografia. Universidad de Oporto, p. 833-839.

Dorta, P. (2001): Aproximación a la influencia de las advecciones de aire sahariano en la propagación de los incendios forestales en la provincia de Santa Cruz de Tenerife. XVII Congreso de la AGE, p. 158-162.

Dorta, P. (2004): Clima y Turismo. Turismo y Territorio en la Sociedad Globalizada. Álvarez, A.; Hernández, J. y Simancas, m. (coords) Turismo y territorio en la sociedad globalizada. Santa Cruz de Tenerife. Ayuntamiento de la Villa de Adeje / Instituto Pascual Madoz del Territorio, Urbanismo y Medio Ambiente, Universidad Carlos III.

Dorta, P. et al. (2002): Algunas consideraciones sobre la importancia del polvo de origen sahariano en el clima del archipiélago canario y su aporte a las aguas superficiales oceánicas: el episodio de abril de 2002. El agua y el clima, AEC, Palma de Mallorca, p. 13-24.

Dorta, P. et al. (2005): Frecuencia, estacionalidad y tendencias de las advecciones de aire sahariano en canarias (1976-2003). Investigaciones Geográficas, 38, p. 23-46.

Elizaga, F. (coord.) (2003): Situación de lluvias torrenciales en Santa Cruz de Tenerife. Madrid, MMA.

García, J. et al. (2001): Invasión de viento sahariano y su impacto en la asistencia sanitaria urgente. Emergencias, 13, p. 372-376.

Gelado et, al. (2003): Caracterización del aerosol sahariano en Gran Canaria. I Encuentro sobre Meteorología y Atmósfera de Canarias. Puerto de La Cruz (Tenerife), Ministerio de Medio Ambiente.

Gómez, $M^{\circ}$.B. (2005): Reflexión Geográfica en torno al binomio Clima-Turismo. Boletín de la AGE, 40, p. 111-134.

Hernández, M. (1990): La muerte en Canarias en el siglo XVIII. La Laguna, Centro de la Cultura Popular Canaria y Ayuntamiento de La Laguna. 
Horcajada, T.; Simancas, M. y Dorta, P. (2000): La constatación y validación de los mapas de riesgo de avenidas en pequeñas cuencas hidrográficas mediante SIG. Propuesta metodológica y aplicación a la ordenación de territorio. Boletín de la AGE, 30, p. 135-154.

Martín Vide, J. (1996): Decálogo de la pluviometría española. Marzol; Dorta y Valladares (eds.) Clima y agua: la gestión de un recurso turístico. Madrid, Tabapres.

Marzol, M.V. (1986): La ola de frío del 29 de enero al 10 de febrero de 1986 en las Islas Canarias. Finisterra, XXII, 43, p. 153-162.

Marzol, M.V. (1987): El régimen anual de las lluvias en el archipiélago Canario. Eria, 14, p. 187-194.

Marzol, M.V. (1988): La lluvia, un recurso natural para Canarias. Santa Cruz de Tenerife. Caja General de Ahorros de Canarias.

Marzol, M.V. (1989): Situaciones atmosféricas de lluvias intensas en Canarias. Reunión cientifica internacional sobre Avenidas fluviales e inundaciones en la cuenca del Mediterráneo, Alicante - Murcia, p. 107 116.

Marzol, M.V. (2001a): La incidencia de las sequías en las Canarias occidentales y orientales, en Causas y consecuencias de las sequias en España. Alicante, CAM e Instituto Universitario de Geografía de la Universidad de Alicante

Marzol, M.V. (2001b): Las sequías meteorológicas: frecuencias e intensidad de la sequedad en las Islas Canarias (España). En Grande, N., Arrojo, P. y Martínez, J. (Coord.). Zaragoza, II Congreso Ibérico sobre planifiación y gestión del agua, p. 1.055-1.065.

Marzol, M.V. (2002): Lluvias e inundaciones en la ciudad de Santa Cruz de Tenerife. El agua y el clima, Palma de Mallorca, El
Agua en el clima, AEC, Serie A, 3, p. 461 470.

Marzol, M.V. (2003): La captación del agua de la niebla en la isla de Tenerife. Santa Cruz de Tenerife, Cajacanarias.

Marzol, M.V. et al. (2006): Los riesgos de las lluvias torrenciales en las islas de la Macaronesia (Azores, Madeira, Canarias y Cabo Verde). Clima, Sociedad y Medio Ambiente, AEC, Serie A, 5, p. 443-452.

Máyer, P. (1999): Un siglo de temporales en la prensa de Gran Canaria. Vegueta, 4, 267-282.

Máyer, P. (2001): Lluvias e inundaciones en la ciudad de Las Palmas de Gran Canaria (1950-1999). El tiempo del clima, Valencia, AEC, Serie A, 2, p. 377-387.

Máyer, P. (2002): Desarrollo urbano e inundaciones en la ciudad de Las Palmas de Gran Canaria (1869-2000). Investigaciones Geográficas, 28, p. 145-159

Máyer, P. (2003a): Riesgos asociados a episodios de lluvia intensa en Gran Canaria (1951-2000). Vector Plus, 22, Fundación Universitaria de Las Palmas, p. 36-42.

Máyer, P. (2003b): Lhuvias e inundaciones en la ciudad de Las Palmas de Gran Canaria (1869-1999). Las Palmas de Gran Canaria. ULPGC y Ayuntamiento de Las Palmas de Gran Canaria.

Máyer, P. y Romero, L. (2006): Causas meteorológicas y distribución espacial de las lluvias intensas en las Canarias orientales (1951-2003). Clima, Sociedad y Medio Ambiente, Zaragoza, AEC, Serie A, 5, p. 453-463.

Quirantes, F. et al. (1993): Los aluviones históricos en Canarias. Nuevos procesos territoriales (XIII Congreso Nacional de Geografia), Sevilla, AGE y Universidad de Sevilla, p. 611-615.

Romero, C. y Yanes, A. (1995): Aproximación a los riesgos naturales de las islas 
Canarias. VI Coloquio Ibérico de Geografia, Oporto, p. 1027-1032.

Romero, L. y Máyer, P. (2002): Episodios de sequía en Gran Canaria en el siglo XVII: análisis de las rogativas como método de reconstrucción climática. El agua y el Clima, Palma de Mallorca, AEC, p. 533542.

Romero, C.; Yanes, A. y Marzol, Ma.V. (2004): Caracterización y clasificación de las cuencas y redes hidrográficas en islas volcánicas atlánticas (Azores, Madeira,
Canarias y Cabo Verde). IV Congreso Ibérico sobre Gestión y Planificación del agua. Tortosa.

Torres-Padrón, M.E. et al. (2002) Variability of dust imputs to the CANIGO zone. DeepSea Research II, 49, p. 3455-3464.

Yanes, A.; Marzol, Ma.V. y Romero, C. (2006): Characterization of sea storms along the coast o Tenerife, the Canary Islands. Journal of Coastal Research, 48 (en prensa). 